\title{
DESEMPENHO PRODUTIVO DE OVELHAS SANTA INÊS SUPLEMENTADAS COM CROMO ORGÂNICO DURANTE A ESTAÇÃO DE MONTA E A GESTAÇÃO
}

\author{
Nelson Parizotto Junior ${ }^{1}$, Wilmar Sachetin Marçal' ${ }^{1}$, Mara Stipp Balarin'1, Vanessa \\ Veronese Ortunho'
}

1 UEL

Correspondência: Nelson Parizotto Junior: nelsonpjunior@yahoo.com.br

\begin{abstract}
RESUMO: O objetivo do presente estudo foi avaliar os efeitos da suplementação dietética com cromo no desempenho produtivo de ovelhas da raça Santa Inês mantidas em pastagem. Foram utilizadas 26 fêmeas multíparas, divididas nos tratamentos Cromo, que consistia na oferta de suplemento protéico-mineral enriquecido com $10 \mathrm{mg} \mathrm{kg}^{-1}$ de cromo orgânico, e Controle, no qual os animais receberam apenas o suplemento protéico-mineral. $O$ peso e a condição corporal das ovelhas foram mensurados nos dias 28, 56, 84, 112, 140, 168 do período experimental, compreendido entre janeiro e julho de 2009. Ao final do experimento, determinou-se a taxa de parição e de prolificidade. O peso ao nascer dos cordeiros foi obtido em até $12 \mathrm{~h}$ após o parto. $\mathrm{O}$ peso vivo e a condição corporal das fêmeas, o peso ao nascer dos cordeiros e as taxas de parição e de prolificidade não foram influenciados pelos tratamentos. A elevação do peso vivo com redução na condição corporal dos animais foi observada com a evolução da gestação. O peso ao nascer não foi diferente entre os sexos, entretanto foi inferior nos cordeiros nascidos de partos duplos. $\mathrm{O}$ cromo não influenciou o desempenho durante a estação reprodutiva e ao longo do período gestacional.
\end{abstract}

Palavras-chave: estresse; gestação; suplementação mineral

\section{PRODUCTIVE PERFORMANCE OF SANTA INES EWES SUPPLEMENTED WITH ORGANIC CHROMIUM DURING THE BREEDING SEASON AND THE PREGNANCY}

\begin{abstract}
The aim of this study was to evaluate the effects of dietetic supplementation with organic chromium in productive performance of Santa Ines ewes kept in the pasture. For carrying out this study, 26 multiparous female sheep were used. They were divided into the Chromium treatment, that consisted in the supply of mineral-protein supplement enriched with $10 \mathrm{mg} \mathrm{kg}-1$ of organic chromium, and control, in which the animals received only the protein-mineral supplement. Their weights and body conditions were checked on days $28,56,84,112,140,168$ of the experimental period, between January and July 2009 . The rates of calving and prolificacy were checked. The lambs were weighed 12 hours after delivering. The live weight and the body condition of the females, the lambs' weights at birth and the rates of prolificacy and calving were not influenced by the treatment. The increase of the live weight with reduction of the body condition of the animals was observed with the evolution of the gestation. The weight at birth did not differ between the sexes; however, it was inferior in the lambs born as twins. Chromium did not influence the performance during the reproductive season and along the gestation period.
\end{abstract}

Key Words: mineral supplementation; pregnancy; stress 


\section{INTRODUÇÃO}

Os primeiros relatos do cromo $(\mathrm{Cr})$ como um mineral traço essencial datam de 1959, devido a estudos com animais de laboratório. Nos anos seguintes, publicaram-se estudos demonstrando quadros de deficiência de $\mathrm{Cr}$, bem como os efeitos positivos de sua suplementação para pacientes humanos recebendo estritamente nutrição parenteral e intolerantes a glicose (Mertz, 1993).

Apesar da demonstração de sua essencialidade ter ocorrido na década 50 , somente nos anos 90 o $\mathrm{Cr}$ passou a ser intensivamente estudado na nutrição dos animais pecuários (Pechova; Pavlata, 2007). Desde então, o foco principal são os animais submetidos ao estresse, condição capaz de induzir a deficiência do mineral. $O$ aumento nos níveis dos glicocorticóides eleva a glicemia sérica, e por consequência a demanda de insulina, proporcionando maior gasto metabólico e excreção do $\mathrm{Cr}$, o que pode causar depleção do pool de reserva do mineral (Vincent, 1999).

\section{Respostas} positivas $a$ suplementação de $\mathrm{Cr}$ no desempenho de animais submetidos ao estresse severo ou crônico ocorrem devido ao restabelecimento da ação insulínica, que contrabalança os efeitos adversos do cortisol, agente imunossupressor e importante antagonista do hormônio pancreático (Möstl; Palme, 2002). Estudos demonstram aumento na ingestão de matéria seca (Yang et al., 1996) e melhoras no estado de saúde dos animais em razão da maior efetividade na resposta imune (Kegley; Spears; Brown Jr., 1996;).

Em trabalho pioneiro, Chang e Mowat (1992) apresentam respostas expressivas para bovinos tratados com $\mathrm{Cr}$ após serem submetidos a longo período de transporte, onde a adição do mineral propiciou um ganho médio diário $30 \%$ superior, enquanto a conversão alimentar reduziu em $27 \%$. Do mesmo modo, Sano et al. (1997) relataram melhor desempenho de ovinos recebendo dieta de alto grão e suplementados com $\mathrm{Cr}$, devido ao alto nível de concentrado atuar como fonte de estresse e em consequência ao seu efeito hiperglicemiante.

O cromo atua também na capacidade reprodutiva dos animais, proporcionando maiores taxas de prenhez, redução no número de serviços por concepção e no intervalo entre partos, resultados associados a potencialização na ação da insulina nos ovários (Stahlhut; Whisnant; Spears, 2006). De maneira menos evidente, este mineral parece aumentar o número de concepções no inicio da estação reprodutiva, 0 que indica efeitos positivos no período pós-parto (Bryan; Socha; Tomlinson, 2004).

Baseado nestes contextos, o presente estudo propõe a análise da influência do $\mathrm{Cr}$ dietético no desempenho produtivo de ovelhas Santa Inês mantidas em pastagem e expostas ao estresse ambiental durante a estação de monta e ao estresse metabólico na fase final de gestação.

\section{MATERIAL E MÉTODOS}

\section{Local, período experimental e separação dos grupos}

O presente estudo foi desenvolvido no município de Marialva - Paraná, situado a $23^{\circ} 29^{\prime} 06^{\prime \prime}$ de latitude sul, $51^{\circ}$ 47'31" longitude oeste e altitude aproximada de $602 \mathrm{~m}$. O clima regional, segundo a classificação de Köppen, é o subtropical úmido (Cfa) com temperatura e precipitação média anual entre 21 e $23^{\circ} \mathrm{C}$ e 1200 a $1400 \mathrm{~mm}$, respectivamente (IAPAR, 2008).

O inicio do período experimental foi em 20 de janeiro de 2009, e este apresentou duração de 182 dias. Durante 56 dias, estendendo-se do início do experimento até o dia 17 de 


\section{Coleta de dados}

As pesagens e as mensurações da condição corporal das fêmeas foram realizadas nos dias $28,56,84,112,140$, 168 do período experimental. Para determinação da condição corporal, utilizou-se o método de palpação da região lombar, graduando-se os resultados de 1 a 5 com intervalos de meio ponto, onde $1=$ muito magro e $5=$ obeso, de acordo com a metodologia proposta por Moraes, Souza e Jaume (2005).

Avaliou-se, ao final do período experimental, a taxa de parição (número de ovelhas paridas em relação às acasaladas) e a taxa de prolificidade (número de cordeiros nascidos em relação as ovelhas acasaladas).

Obteve-se o peso ao nascer dos cordeiros em no máximo $12 \mathrm{~h}$ após o parto.

Para monitoração do ambiente, foram coletadas leituras de temperatura e de umidade no interior do aprisco a cada 10 minutos, durante o período que os animais permaneceram na instalação, utilizando-se um medidor datalogger com capacidade para 32000 leituras. Calculou-se então as médias diárias de temperatura e de umidade e o índice de temperatura e umidade (ITU), apresentados na Tabela 2, de acordo com a seguinte equação proposta por Marai et al. (2007):

ITU $=$ TA $-\{(0.31-0.31$ UR) $(T A-14.4)\}$,

Onde: $\mathrm{TA}=$ Temperatura ambiente em ${ }^{\circ} \mathrm{C}$

$\mathrm{UR}=$ Umidade relativa em decimais

Tabela 2 - Avaliação das condições ambientais e do nivel de estresse durante 0 período experimental na região de Marialva-PR.

\begin{tabular}{|c|c|c|c|c|c|c|c|}
\hline \multirow{2}{*}{$\begin{array}{l}\text { Cond. } \\
\text { Amb. }\end{array}$} & \multicolumn{7}{|c|}{ Period o experimental } \\
\hline & Janeiro & Fevereiro & Março & Abril & Maio & Junho & Julho \\
\hline$T M D^{2}$ & 25,5 & 27,2 & 25,5 & 23,6 & 18,9 & 17,6 & 18,3 \\
\hline$U M D^{3}$ & 77,5 & 76,1 & 68,2 & 64 & 75,3 & 77,2 & 78,6 \\
\hline $1 T U^{4}$ & 24,7 & 26,25 & 24,41 & 22,57 & 18,56 & 17,37 & 18,04 \\
\hline$N E^{5}$ & Severo & Severo & Severo & Moderado & Ausência & Ausência & Ausência \\
\hline
\end{tabular}

O nível de estresse a que os animais foram expostos, demonstrado também na Tabela 2, foi determinado utilizando-se uma escala de graduação do ITU, onde índices menores que 22,2 indicam ausência, índices oscilando entre 22,2 a 23,29 e 23,3 a 25,59 significam níveis moderados e severos, respectivamente, e valores superiores a 25,6 determinam estresse extremamente severo (Marai et al., 2007).

\section{Coleta de material biológico}

As amostras de fezes utilizadas nos exames coproparasitológicos foram colhidas diretamente da ampola retal, sendo este material resfriado e processado na data da coleta.

\section{Análises laboratoriais}

As análises foram realizadas no Laboratório de Parasitologia do Hospital Veterinário da Universidade Estadual de Londrina. Para quantificação do número de ovos por grama de fezes (OPG) procedeu-se a técnica de Gordon e Whitlock modificado em concordância com o referido por Hoffman (1987), que consiste na flutuação dos ovos em solução supersaturada de $\mathrm{NaCl} e$ posterior contagem na câmara de McMaster.

\section{Análise estatística}

Os resultados foram distribuídos entre as fases gestacionais (inicial - dias 0 a 50; média - dias 51 a 100; final - dia 101 até o parto) gerando médias para cada uma delas. Utilizando-se o programa de análises estatísticas SAS (SAS, 1994), os dados foram submetidos à análise de variância, empregando-se um modelo que considerou os efeitos dos tratamentos (cromo e controle) e dos períodos gestacionais (apresentados acima) para as variáveis peso vivo e condição corporal. Para analisar o peso ao nascer dos cordeiros, o modelo estatístico incluiu os efeitos dos tratamentos (cromo e controle), do tipo de parto (simples e gemelar) e do sexo do cordeiro (macho e fêmea). Para avaliar o contraste entre as médias utilizou-se o teste de Tukey, ao nível de significância de $5 \%$. As taxas de parição e prolificidade, por se tratarem de 
Desempenho produtivo de ovelhas Santa Inês suplementadas com cromo orgânico durante a estação de monta e a gestação

proporções, foram submetidas ao teste do Qui-quadrado a 5\%.

\section{RESULTADOS E DISCUSSÃO}

Os valores referentes à variação no peso vivo e na condição corporal dos animais, em função dos tratamentos e da fase da gestação, são apresentados na tabela 3 .

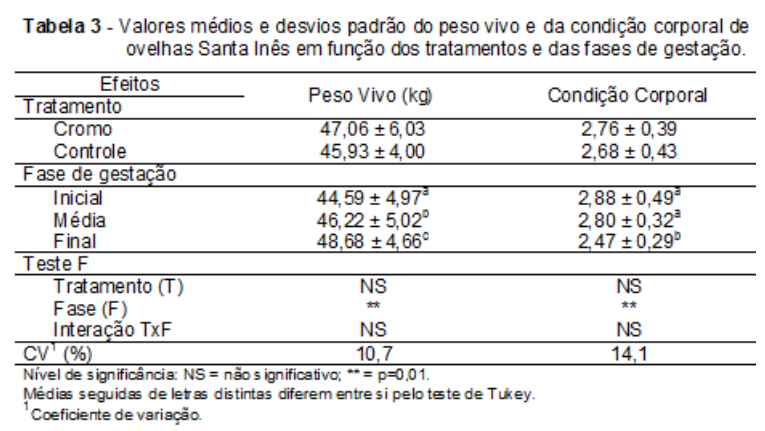

Conforme demonstrado, o Cr não influenciou o peso vivo e a condição corporal dos animais (Kitchalong et al., 1995). A ausência de efeitos positivos foi relatada também em experimento com suínos (Amoikon et al., 1995), bezerros lactentes (Kegley; Spears; Brown Jr, 1996;) e bovinos durante a fase de recria (Bunting et al., 1994) e em confinamento (Swanson et al., 2000). Contudo, não são raros os trabalhos apresentando elevação na produtividade durante ou após condições de estresse, em razão do maior consumo de matéria seca e da melhora no status imune (Chang; Mowat, 1992; Gentry et al., 1999).

A efetividade da inclusão dietética do $\mathrm{Cr}$ esta diretamente relacionada ao tipo, a duração e a intensidade do estresse a que os animais são expostos (Arthington et al., 1997). No presente estudo, durante os meses iniciais do experimento (entre os meses de janeiro a março), o clima propiciou condições severas de estresse, principalmente devido a alta umidade relativa do ar, bastante acima dos níveis de conforto $(\mathrm{UR}=30 \%)$ referidos por Marai et al. (2007) (Tabela 2). Entretanto, a maior tolerância a ambientes desfavoráveis da raça avaliada pode ter reduzido os efeitos adversos sobre o metabolismo do cromo, de maneira a não causar depleção nas reservas corporais (Kitchalong et al., 1995).

Nos período final do experimento (entre os meses de junho e julho), os fatores estressantes foram as alterações metabólicas presentes no terço final de gestação (Bauman; Currie, 1980). É possível que a realização do estudo apenas com fêmeas multíparas tenha contribuído para ausência de efetividade devido ao menor estresse metabólico nesta categoria. Isto foi demonstrado por Yang et al. (1996) que suplementaram bovinos leiteiros de diferentes categorias com $\mathrm{Cr}$ e observaram aumento significativo de $15 \%$ no consumo de matéria seca e tendência de produção de leite superior em primíparas, mas não em vacas multíparas. Outros fatores a serem considerados são os níveis e a biodisponibilidade da forma química do mineral na dieta basal, pois se adequados, podem justificar a ineficiência de sua inclusão (Kegley; Galloway; Fakler, 2000).

A elevação do peso vivo dos animais nas fases inicial e média da gestação ocorre devido ao acumulo de líquidos no útero e ao desenvolvimento dos anexos fetais, enquanto no período final, o crescimento do(s) concepto(s) é o principal agente. Aos 70 dias de prenhez, o feto representa apenas $14 \%$ do conteúdo uterino, enquanto as membranas correspondem a $37 \%$ e os fluidos a $49 \%$. No dia 140, fetos, membranas e fluidos representam 70,8 e $22 \%$, respectivamente (Rettray et al., 1974).

A redução na condição corporal na fase final pode ser explicada pela maior demanda nutricional associada ao menor consumo de alimento. Nesse período o requerimento energético total equivale a 1,5 e 2 vezes as necessidades de mantença, que são 
atendidas pela mobilização das reservas corporais (NRC, 1985). Isso significa maior mobilização dos ácidos graxos não esterificados a partir da hidrólise dos triglicerídeos armazenados no tecido adiposo e aumento na gliconeogênese a partir de aminoácidos originados da proteólise do tecido muscular (Bell, 1995).

A menor ingestão de matéria seca deve-se ao aumento no volume uterino que causa compressão do trato gastrointestinal, reduzindo a capacidade física de enchimento do rúmen; a elevação nos níveis séricos de hormônios como estrógeno e insulina; e as maiores taxas de oxidação dos ácidos graxos livres e de produção de $\beta$ hidroxibutirato no fígado, que atuam de maneira intensa como redutores do consumo (Ingvartsen; Andersen, 2000).

Os resultados obtidos referentes aos índices reprodutivos são apresentados na Tabela 4. As taxas de parição e de prolificidade não diferiram entre os tratamentos. O alto valor do primeiro índice pode ser atribuído ao fato de que a condição corporal das fêmeas esteve próxima a 3 durante a ER, o que segundo Moraes, Souza e Jaume (2005) é o patamar mínimo para a obtenção de uma produtividade ótima. No Rio Grande do Sul, rebanhos comerciais com condição corporal média de 2,84 no inicio da estação de monta apresentaram mais de $90 \%$ de prenhez (Ribeiro et al., 2003). Ainda segundo estes autores, para o aumento de cada ponto nesta escala a chance de concepção é 1,89 vezes maior.

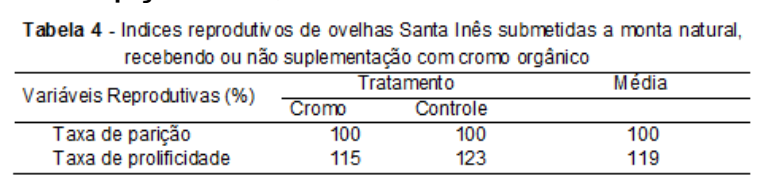

Os resultados observados na taxa de prolificidade divergem dos obtidos em suínos, onde o cromo foi capaz de elevar este índice, aumentando o número de leitões nascidos e nascidos vivos (Lindemann et al., 2004). A prolificidade média do rebanho experimental foi inferior a obtida em estudo realizado por Mexia et al. (2004) na região noroeste do Paraná, onde $25 \%$ dos partos foram gemelares.

Os resultados das pesagens ao nascimento, agrupados de acordo com as fontes de variação, são apresentados na Tabela 5. O peso médio ao nascer $(3,73 \mathrm{~kg})$ foi superior ao apresentado por Rocha et al. (2009) e inferior ao relatado por Barros et al. (2005) para cordeiros $F_{1}$ Dorper $x$ Santa Inês. Este parâmetro não foi influenciado pelo tratamento e pelo sexo dos cordeiros ou ainda pela interação entre as variáveis. De modo semelhante, a adição de Cr no suplemento mineral ofertado para fêmeas bovinas no terço final de gestação não afetou o peso ao nascer e ao desmame, e a taxa de morbidade dos bezerros (Stahlhut; Whisnant; Spears, 2006). Ao analisar a variável sexo, diversas pesquisas utilizando os mesmos grupos genéticos ou com proximidade geográfica apresentaram resultados semelhantes (Silva; Araújo, 2000; Ribeiro et al., 2002; Barros et al., 2005; Rocha et al., 2009).

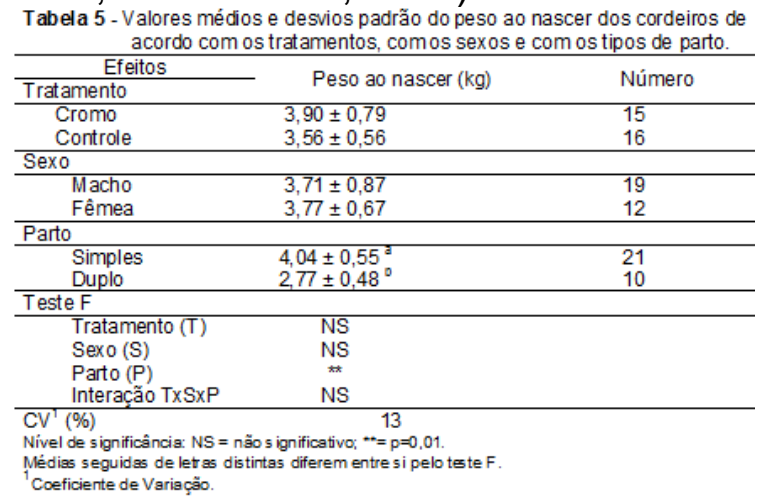

Os cordeiros nascidos de parto duplos foram aproximadamente $31 \%$ mais leves que os nascidos de partos simples. Estes resultados foram próximos ao valor de $27 \%$ obtidos por Ribeiro et al. (2002) analisando diferentes grupos genéticos na região norte do Paraná. Outros trabalhos relatam maior peso ao nascer na ordem de 17 a 20,5\% quando apenas um cordeiro é gestado (Silva; Araújo, 2000; 
Desempenho produtivo de ovelhas Santa Inês suplementadas com cromo orgânico durante a estação de monta e a gestação

Rocha et al., 2009). Segundo Barros et al., (2005) esta diferença é mantida durante o restante da vida produtiva do animal e se deve a menor competição intra uterina por nutrientes e ausência de competição pelo alimento durante o aleitamento.

\section{CONCLUSÃO}

O cromo não influenciou as variáveis analisadas nas condições em que 0 estudo foi desenvolvido. A evolução da gestação ocasionou a elevação no peso vivo associado a redução na condição corporal das ovelhas. Os cordeiros nascidos de partos duplos apresentaram menor peso ao nascer.

\section{AGRADECIMENTOS}

A CONNAN, Companhia Nacional de Nutrição Animal, pelo apoio técnico e financeiro.

\section{NOTAS INFORMATIVAS}

\author{
Registrado no CEEA/UEL sob o \\ número 32/08.
}

\section{REFERÊNCIAS}

AMOIKON, E. K.; FERNANDEZ, J. M.; SOUTHERN, L. L. et al. Effect of chromium tripicolinate on growth, glucose tolerance, insulin sensitivity, plasma metabolites, and growth hormone in pigs. Journal of Animal Science, v.73, n.4, p.1123-1130, 1995.

ARTHINGTON, J. D.; CORAH, L. R.; MINTON, J. E. et al. Supplemental dietary chromium does not influence ACTH, cortisol, or immune responses in young calves inoculated with bovine herpesvirus-1. Journal of Animal Science, v.75, n.1, p.217-223,1997.

BARROS, N. N.; VASCONCELOS, V. R.; WANDER, A. E. et al. Eficiência bioeconômica de cordeiros $F_{1}$ Dorper $x$ Santa Inês para produção de carne. Pesquisa Agropecuária Brasileira, v.40, n.8, p.825-831,2005.
BAUMAN, D. E.; CURRIE, B. C. Partitioning of nutrients during pregnancy and lactation: a review of mecanims involving homeostasis and homeorhesis, Journal of Dairy Science, v.63, n.9, p.1514-1529,1980.

BELL, A. W. Regulation of organic nutrient metabolism during transition from late pregnancy to early lactation. Journal of Animal Science, v.73, n.9, p.2804-2819,1995.

BOWMAN, J. G.; SOWELL, B. F. Delivery method and supplement consumption by grazing ruminants: a review. Journal of Animal Science, v.75, n.2, p.543-550,1997.

BRYAN, M. A.; SOCHA, M. T.; TOMLINSON, D. J. Supplementing Intensively Grazed LateGestation and Early-Lactation Dairy Cattle with Chromium. Journal of Dairy Science, v. 87, n.12, p. 4269-4277, 2004.

BUNTING, L. D.; FERNANDEZ, J. M.; THOMPSON JR, D. L. et al. Influence of chromium picolinate on glucose usage and metabolic criteria in growing Holstein calves. Journal of Animal Science, v.72, n.6, p.15911599,1994.

CHANG, X.; MOWAT, D. N. Supplemental chromium for stressed and growing feeder calves. Journal of Animal Science, v.70, n.3, p. 559-565, 1992.

GENTRY, L. R.; FERNANDEZ, J. M.; WARD, T. L. et al. Dietary protein and chromium tripicolinate in Suffolk wether lambs: effects on production characteristics, metabolic and hormonal responses, and immune status. Journal of Animal Science, v.77, n.5, p.12841294, 1999.

HOFFMANN, R. P. Diagnóstico de parasitismo veterinário. Porto Alegre: Sulina, 1987.

IAPAR. Cartas Climáticas. Disponível em: $<$ www. iapar.br> acesso em: 18 jul. 2008.

INGVARTSEN, K. L.; ANDERSEN, J. B. Integration of metabolism and intake regulation: a review focusing on periparturient animals, Journal of Dairy Science, v. 83, p. 1573-1597, 2000.

KEGLEY, E. B.; GALLOWAY, D. L.; FAKLER, T. M. Effect of dietary chromium-L-methionine on glucose metabolism of beef steers. Journal of Animal Science, v.78, n.12, p.3177-3183,2000. 
KEGLEY, E. B.; SPEARS, J. W.; BROWN JR, T. T. Immune Response and Disease Resistance of Calves Fed Chromium Nicotinic Acid Complex or Chromium Chloride. Journal of Dairy

Science, v.79, n.2, p.1278-1283,1996.

KITCHALONG, L.; FERNANDEZ, J. M.; BUNTING, L. D. et al. Influence of chromium tripicolinate on glucose metabolism and nutrient partitioning in growing lambs, Journal of Animal Science, v.73, n.9, p.2694-2705,1995.

LINDEMANN, M. D.; CARTER, S. D.; CHIBA, L. I. et al. Regional evaluation of chromium tripicolinate supplementation of diets fed to reproducing sows. Journal of Animal Science, v.82, p.2972-2977,2004.

MARAI, I.F.M.; EL-DARAWANY, A.A.; FADIEL A. et al. Physiological traits as affected by heat stress in sheep - A review. Small Ruminant Research, v.71, n.1, p.1-12, 2007.

MERTZ, W. Chromium in human nutrition: a review. The Journal of Nutrition, v.123, n.4, p.626-633,1993.

MEXIA, A. A.;MACEDO, F. A. F.; ALCALDE, C. $R$. et al. Desempenhos reprodutivo e produtivo de ovelhas Santa Inês suplementadas em diferentes fases da gestação. Revista Brasileira de Zootecnia, v.33, n.3, p.658-667, 2004.

MORAES, J. C. F.; SOUZA, C. J. H.; JAUME, C. J. O Uso da Avaliação da Condição Corporal Visando Máxima Eficiência Produtiva dos Ovinos. Bagé: Embrapa, 2005. (comunicado técnico 57).

MÖSTL, E; PALME, R. Hormones as indicators of stress. Domestic Animal Endocrinology, v. 23, p. 67-74, 2002.

NATIONAL RESEARCH COUNCIL. Nutrient Requirement of Sheep. 6 ed. Washington: National academic press, 1985.

NATIONAL RESEARCH COUNCIL. The Role of Chromium in Animal Nutrition, Washington: National academic press, 1997.

PECHOVA, A.; PAVLATA,L. Chromium as an essential nutrient: a review, Veterinary Medicine, v.52, n.1, p.1-18, 2007.

RETTRAY, P. V.; GARRETT, W. N.; EAST, N. E. et al. Growth, development and composition of the ovine conceptus and mammary gland during pregnancy. Journal of Animal Science, v.38, n.3, p.613-626, 1974 .
.RIBEIRO, E. L. A.; SILVA, L. D. F.; MIZUBUTI, I, Y. et al. Desempenho produtivo de ovelhas acasaladas no verão e no outono recebendo ou não suplementação alimentar durante o acasalamento. Semina: Ciências Agrárias, v.23, n.1, p.35-44, 2002.

RIBEIRO, L. A. O.; FONTANA, C. S.; WALD, V. B. et al. Relação entre a condição corporal e a idade das ovelhas no encarneiramento com a prenhez. Ciência Rural, v.33, n.2, p.357-361, 2003.

ROCHA, L. P.; FRAGA, A. B.; ARAUJO FILHO, J. T. et al. Desempenho de cordeiros cruzados em Alagoas, Brasil. Arquivos de Zootecnia, v.58, n.221, p.145-148, 2009.

SANO, H.; MOWAT, D. N.; BALL, R. O. et al. Effect of Supplemental Chromium on WholeBody Kinetics of Glucose, Lactate, and Propionate in Rams Fed a High Grain Diet. Compendium Biochemistry and Physiology, v.118, n.1, p.117-121, 1997.

STATISTICAL ANALYSES SYSTEMS - SAS. SAS/STAT: user's guide. Cary: 1994. v.2,846p.

SILVA, F. L. R.; ARAÚJO, A. M. Características de Reprodução e de Crescimento de Ovinos Mestiços Santa Inês, no Ceará. Revista Brasileira de Zootecnia, v.29, n.6, p.17121720, 2000.

STAHLHUT, H. S.; WHISNANT, C. S.; SPEARS, J. W. Effect of chromium supplementation and copper status on performance and reproduction of beef cows. Animal Feed Science and Technology, v.128, n.3-4, p.266-275, 2006.

SWANSON, K. C.; HARMON, D. L.; JACQUES, K. A. et al. Efficacy of chromium-yeast supplementation for growing beef steers. Animal Feed Science and Technology, v.86, n.1, p.95105, 2000.

UNDERWOOD, W. J.; SUTTLE, N. F. The Mineral Nutrition on Livestock, 3 ed. Wallingford: CAB international, 1999.

VINCENT, J. B. Mechanisms of chromium action: low-molecular-weight chromium-binding substance. Journal of the American College of Nutrition, v.18, n.1, p.6-12, 1999.

YANG, W. Z.; MOWAT, D. N.; SUBIYATNO, A. et al. Effects of chromium supplementation on early lactation performance of Holstein cows. Canadian Journal of Animal Science, v.76, n.2, p. 221-230, 1996. 